\title{
O LADO MENOS CONHECIDO DA HISTÓRIA DA PRIMEIRA TRADUÇÃO DE GRANDE SERTÃO: VEREDAS PARA O INGLÊS
}

\section{THE LESS KNOWN SIDE OF THE STORY OF THE FIRST TRANSLATION OF GRANDE SERTÃO: VEREDAS INTO ENGLISH}

\section{Lenita Maria Rimoli Pisetta*}

\section{RESUMO}

A tradução de Grande sertão: veredas para o inglês, feita por Harriet de Onís e o Professor James Taylor e publicada no início da década de 1960, é em geral considerada insuficiente, não fazendo jus ao original de Guimarães Rosa. A parte mais conhecida da história dessa tradução é apresentada em trabalhos que têm como fonte principal as cartas trocadas entre Guimarães Rosa e Harriet de Onís, que estão no acervo JGR do Instituto de Estudos Brasileiros (IEB) da Universidade de São Paulo. Com base em trabalhos já publicados sobre o assunto e na análise de cartas trocadas entre a tradutora Harriet de Onís e os editores da Alfred A. Knopf, o objetivo deste trabalho é esclarecer melhor alguns fatos que parecem ter ficado em segundo plano, principalmente a atuação de Harriet de Onís para "defender" sua tradução e a escrita singular de João Guimarães Rosa. Como apoio para a discussão, recorreremos às autoras Pascale Casanova e Emily Apter e suas visões sobre a "Literatura Mundial".

Palavras-chave: Grande sertão: veredas, João Guimarães Rosa; Literatura Mundial, Harriet de Onís; Alfred A. Knopf, Inc.

\section{ABSTRACT}

The devil to pay in the backlands, the translation of Grande sertão: veredas into English by Harriet de Onís and Professor James Taylor published in the beginning of the 1960s, is generally considered insufficient, not living up to Guimarães Rosa's original. The better known part of the story of this translation is presented in papers that use as their main source the letters exchanged between Guimarães Rosa and Harriet de Onís, which are in the JGR collection at the Brazilian Studies Institute (IEB - Instituto de Estudos Brasileiros) at the University of São Paulo - Brazil. Based on papers already published about this subject and on the analysis of letters exchanged between translator Harriet de Onís and the editors at Alfred A. Knopf, Inc., this paper aims at better clarifying some facts that seem to have remained in the background, especially De Onís's efforts to advocate for her translation and the singularity

\footnotetext{
* Universidade de São Paulo, USP, São Paulo, SP, Brasil. lenitarimolip@usp.br Orcid: https://orcid.org/0000-0003-0525-5048

Agradeço à FAPESP pela concessão de bolsa que possibilitou a pesquisa feita para este trabalho. Processo: 2019/00319-3
} 
of João Guimarães Rosa's text. As a support to the discussion, we resort to Pascale Casanova and Emily Apter and their visions about "World Literature".

Keywords: The devil to pay in the backlands: João Guimarães Rosa; World Literature; Harriet de Onís; Alfred A. Knopf, Inc.

\title{
INTRODUÇÃO: THE DEVIL TO PAY IN THE BACKLANDS COMO UM MEME DA LITERATURA BRASILEIRA TRADUZIDA?
}

O Dicionário Houaiss eletrônico define "meme" como: "1 informação visual ou textual que se espalha pela rede; 1.1 freq. crítica humorística sobre fato ou pessoa que foi notícia (MEME, s.d.). Já a Wikipedia nos complementa a informação:

\begin{abstract}
Na sua forma mais básica, meme é tudo aquilo que os utilizadores da Internet repetem, simplesmente uma ideia que é propagada através da World Wide Web. Esta ideia pode assumir a forma de um hiperlink, vídeo, imagem, website, hashtag, ou mesmo apenas uma palavra ou frase. Este meme pode se espalhar de pessoa para pessoa através das redes sociais, blogs, e-mail direto, fontes de notícias e outros serviços baseados na web tornando-se geralmente viral (MEME (Internet), s. d.).
\end{abstract}

Segundo essa mesma fonte, as características mais marcantes dos memes são sua repetição e rápida difusão. Refiro-me humoristicamente a The devil to pay in the backlands como um meme da literatura brasileira traduzida porque essa obra carrega consigo uma espécie de rótulo indelével, que a marca e a desqualifica como "insuficiente", "empobrecedora" e "literal", entre outras qualificações. ${ }^{1}$ Iná Valéria Verlangieri, embora não use o termo "meme", parece pensar de forma convergente com a nossa, quando observa que até um colunista social escreveu "explicando" o pouco entusiasmo causado pela tradução de Grande sertão: veredas em inglês (VERLANGIERI, 1993, p. 23).

Essa ideia meio genérica e espalhada sobre essa tradução se origina na opinião de teóricos e estudiosos que se debruçaram sobre o assunto, mas acaba sendo simplificada e estereotipada ao ser repetida em manifestações pouco informadas. Mesmo assim, as opiniões abalizadas parecem reforçar a ideia de que a tradução é inadequada, como será possível observar a seguir. A primeira citação é retirada de uma resenha escrita por William Grossman, uma das primeiras a serem publicadas

1. Só para ficarmos num único exemplo: os comentários que acompanham um vídeo postado em 2014 no YouTube, no qual Haroldo de Campos fala sobre Grande sertão: veredas e comenta apenas de passagem a tradução para o inglês, encontramos o seguinte comentário: "Dizem que a melhor tradução é para o alemão, talvez porque Rosa juntava palavras pra compor outras, recurso muito usado nesse idioma". O início do comentário já traz uma característica de meme. Alguém ouve dizer em algum lugar e sai repetindo, e a ideia se espalha e multiplica. (GRANDE, 2014, ênfase minha). 
logo que The devil foi lançada nos EUA. As citações seguintes são mais recentes, como se observa nas datas das referências:

...much of the color is drained from the book" (GROSSMAN (1963), apud ROSTAGNO, 1997, p. 44).

An admirable competent betrayal of the original, from the title on (VINCENT, 1978, p. 71).

The impoverished and excerpted translation of the Brazilian author`s masterpiece (MERRIM, 1982, p. 211).

The result is a more readily digestible text, but one which loses certain graces (ARMSTRONG, 2001, p. 72).

In the North American case, while linguistically flawed on many small points... (ARMSTRONG, 2001, p. 79).

Eu considero The devil to pay in the backlands como uma tradução "falhada" porque distorce e interpreta mal o texto original de uma forma consistente (KRAUSE, 2013, p. 209)

The devil to pay in the backlands is one of the best case studies of unfulfilled expectations (KRAUSE, 2015, p. 113).

...Onís and Taylor watered down the brilliance of the original. (KRAUSE 2015, p. 118).

Antes de entrarmos especificamente na discussão proposta aqui para iluminar aspectos que talvez tenham ficado em segundo plano, convém recordar alguns fatos que, se para as pessoas mais próximas ao assunto das traduções de Rosa para o inglês podem ser conhecidos, talvez não tenham sido muito bem-detalhados para outros. O leitor que estiver inteirado sobre como aconteceu essa tradução pode, se preferir, dirigir-se à próxima seção deste trabalho.

\section{FATOS QUE TALVEZ JÁ SEJAM CONHECIDOS, MAS QUE VALE A PENA RELEMBRAR}

- The devil to pay in the backlands foi a primeira tradução de Grande sertão: veredas. (VERLANGIERI，1993， p. 18; ARMSTRONG，1999， p. 116; 2001， p. 65; KRAUSE, 2015, p. 114).

- Harriet de Onís foi a "descobridora" de Rosa, por meio de uma tradução para o espanhol de "A hora e a vez de Augusto Matraga". Ela convenceu Alfred Knopf da qualidade da obra de Rosa e foi a primeira a contatar o escritor com vistas a traduzi-lo para o inglês. (VERLANGIERI, 1993, p. 18; ROSTAGNO, 1997, p. 
42-3; ARMSTRONG, 1999, p. 97; ANDRADE, 2010, p. 45; LIVINGSTONE, 2015 , p. $114 ; 129)$

- Harriet de Onís iniciou a tradução e fez uma primeira versão de um terço da obra, que achou melhor passar às mãos de James Taylor, lexicógrafo especialista em português brasileiro e professor da Stanford University. Ela indicou Taylor, que foi aceito por Knopf (VERLANGIERI, 1993, p. 19; ARMSTRONG, 1999, p. 97; 2001, p. 65-6; ANDRADE, 2010, p. 45; LIVINGSTONE, 2015, pp. 12933; KRAUSE, 2015, p. 114).

- Houve muito menos troca de cartas entre Rosa e Harriet de Onís para a tradução de Grande sertão: veredas do que para a tradução de Sagarana, feita por ela posteriormente. Rosa alegou estar com problemas de saúde e delegou a tarefa de esclarecer as dúvidas de Harriet Onís à Sra. Oliver, uma inglesa professora de inglês de uma grande amiga sua. Esse arranjo não trouxe bons frutos (VERLANGIERI, 1993, p. 19; KRAUSE, 2013, p. 222-23; 2015, p. 121; LIVINGSTONE, 2015, p. 131-142; ANDRADE, 2010, p. 41).

- Rosa coletou 27 resenhas de The Devil publicadas em 1963 (PERRONE, 2003, p. 90).

- Rosa estava disposto a fazer importantes concessões para ter o livro traduzido para o inglês, o que enxergava como um importante passo para a internacionalização de sua obra. (ARMSTRONG, 2001, p. 70; PERRONE, 2003, p. 92; VIOTTI, 2007, p.40; GRANDE, 2014, 22:20-23-13m; LIVINGSTONE, 2015, p. 132; KRAUSE, 2015, p. 114).

- Parece ser ponto pacífico o fato de que The devil to pay, apesar de todos os esforços de tradutores e editores, não atingiu popularidade nos EUA, como aconteceu, por exemplo, com Gabriela, clove and cinammon, de Jorge Amado, que chegou ao primeiro lugar da lista dos mais vendidos naquele país. Parte dos estudiosos atribui o fracasso à inadequação da tradução, ao passo que outros questionam essa suposição (ARMSTRONG, 2001, p. 76; PERRONE 2003, p. 91; KRAUSE, 2013, p. 226; LIVINGSTONE, 2015, p. 113; 136-137).

- A obra foi recebida nos EUA como um tipo de western, e não revelou ao leitor estadunidense todo o trabalho de linguagem de Rosa, que é fundamental para a sua apreciação. O livro, de acordo com muitos estudiosos, caiu numa espécie de vácuo crítico (VINCENT, 1978, p. 71; PERRONE, 1987, p.123; 2003, p. 
90; ROSTAGNO, 1997, p. 44; ARMSTRONG, 1999, p. 120; 2001, p. 72-73; GRANDE, 2014, 23:20-23:34m; LIVINGSTONE, 2015, p. 120-121; KRAUSE, 2015, p. 113-14).

\section{2. "JÁ NÃO ERA SEM TEMPO..."}

É fato amplamente divulgado que Grande sertão: veredas está sendo retraduzido por Allison Entrekin com apoio do Itaú Cultural. No caso dessa obra e sua tradução para o inglês, não seria preciso discutir a conveniência de uma nova tradução. Todos parecem concordar com o fato de o texto em inglês não fazer jus ao original em português. Mas será que é sempre assim? Serão as retraduções sempre necessárias depois de passado algum tempo? No caso da língua inglesa, a tendência dos tradutores a dar mais ênfase para o enredo do que para o trabalho com a linguagem parece ser um argumento bastante forte para uma retradução. O próprio Rosa, em sua troca de cartas com tradutores, já manifestava que na versão inglesa a obra perdia muitas de suas características fundamentais. Por outro lado, o mesmo Rosa achava importante ter sua obra traduzida para o inglês, o que representaria um trampolim para a sua internacionalização. ${ }^{2}$

Mas e a tradução alemã, feita por Curt Meyer-Clason? A tradução que Rosa vaticinou que seria a "tradução verdadeira", a "tradução-mãe", a "tradução-base" ?? Será que esse trabalho precisaria de retoques ou mereceria ser refeito? Pois bem, como muitos sabem, existe uma retradução alemã em andamento. O novo tradutor, Berthold Zilly, que já verteu obras de outros brasileiros, inclusive Os sertões, afirma

2. Muitos críticos já comentaram as trocas de cartas. Piers Armstrong é arguto ao afirmar que Rosa era um diplomata também no trato com seus tradutores. Dizia para Harriet de Onís que a perda linguística não era algo tão grave, ao mesmo tempo em que lamentava para o tradutor alemão que o livro americano "está cheio de falhas", e que a tradução alemã deverá servir de referência para as outras. O que não o impede de, no ano seguinte, escrever para o tradutor italiano afirmando que não "haverá tradução melhor que a sua" (ARMSTRONG, 2001, p. 68-70).

3. No mesmo artigo já citado, Armstrong faz a interessante observação de que as críticas à tradução para o inglês (que ele admite ter vários problemas) em geral são vagas e provavelmente baseadas em "bearsay". (Mais uma vez, o meme...). Por outro lado, a ampla aceitação da tradução alemã parece basear-se mais nas esperanças de Rosa, ou ainda no que ele escolheu declarar ao tradutor alemão do que em uma sólida análise do resultado final da tradução (ARMSTRONG, 2001, p. 75). O trabalho de Fábio Luiz Chiqueto Barbosa argumenta que "até hoje as traduções alemãs da obra de Rosa são infundadamente celebradas como as melhores, as mais bem acabadas e realizadas versões que existem de seus textos, sobretudo no que se refere ao romance Grande sertão: veredas" (BARBOSA, 2010, p. 64), conclusão a que chega depois de analisar o texto em alemão e concluir que ele "pende para a univocidade de sentidos, jogando para planos secundários os sentidos polifônicos que emergem intrinsecamente à obra na composição de suas imagens. A consequência é que também os planos superpostos da configuração da realidade física são castrados" (BARBOSA, 2010, p. 67). 
ter iniciado a tradução em meados de 2011 e a princípio esperava concluí-la em 2015 (REBINSKI JÚNIOR, s. d.).

Em uma palestra ministrada durante a Feira do Livro de Niterói em 2014, Berthold Zilly afirma que a ideia da retradução não partiu dele, mas do editor, que é grande admirador de Guimarães Rosa. Além disso, Zilly justifica o trabalho com as seguintes observações:

a língua muda, a língua alemã muda como qualquer língua, as ideias sobre tradução mudam, e também as expectativas do público. [Isso] não quer dizer que a tradução antiga ou anterior deve ser condenada ou colocada de lado... (ZILLY, 2018, 36:00-36:50m).

Parece haver uma crença genérica de que as traduções envelhecem, ao passo que os originais permanecem sempre vivos e atuais (outro meme?). Em trabalho anterior, elenquei alguns autores que tratam do assunto da retradução. Um dos motivos mais citados é também o mais óbvio: o editor considera que a tradução não está mais adequada, que ela envelheceu, ou que a primeira edição continha erros ou omissões (LOWE, apud ESTEVES, 2016, p. 658). Destaca-se a visão de Yves Gambier, segundo o qual "a tradução é um retorno desviado", que exige um tempo. Uma retradução se aproximaria mais do original, sendo mais ousada, já que a cultura de chegada estaria, depois de um tempo de convivência com a primeira tradução, preparada para aceitar as particularidades da obra, que não seriam bem aceitas em uma primeira etapa (GAMBIER, apud ESTEVES, 2016, p. 658-9).

No caso da retradução de Grande sertão: veredas, além desse motivo óbvio o da inadequação - devemos também levar em conta uma conjunção de fatores: alguém disposto a assumir essa tarefa hercúlea e ter capacidade para fazê-lo e haver apoio financeiro para a sua realização. Além disso, é preciso que editoras queiram republicar a obra. No caso de Grande sertão, a editora será a mesma da primeira tradução nos EUA, A Alfred A. Knopf, e no Reino Unido será a Jonathan Cape (CARREIRO, 2017).

No caso da primeira tradução, Harriet de Onís foi sem dúvida a maior motivadora, já que "descobriu" Rosa ao ler um conto seu publicado em espanhol, entrou em contato com o autor e o recomendou para a Alfred A. Knopf, Inc. Além disso, para entender como essa tradução foi realizada, é preciso considerar vários outros fatores. The devil to pay in the backlands veio à luz num ambiente de quase desconhecimento dos autores brasileiros pelos leitores estadunidenses; numa época em que faltavam estudos críticos sobre a obra e poucos eram os recursos à disposição dos tradutores: uma máquina de escrever, alguns dicionários, alguma enciclopédia. Mas nada das maravilhas da Internet. Nesse contexto, a perspicácia editorial da tradutora Harriet de Onís impediu até certo ponto que o romance de Rosa fosse 
ainda mais alterado e empobrecido só para agradar ao gosto do leitor dos EUA. As cartas trocadas entre de Onís e a editora a revelam como uma tradutora que, além de ter uma aguda percepção estética, também tinha seus dotes diplomáticos, e soube defender, até onde pôde, a singularidade da obra de Rosa.

Antes de passarmos ao exame das cartas, porém, é interessante mencionarmos duas obras que tratam da posição das obras provindas de culturas não hegemônicas no contexto internacional. A República mundial das letras, de Pascale Casanova, lançado na França em 1999 e no Brasil em 2002, oferece uma visão das trocas literárias entre centros literários tendo em vista aspectos como o predomínio de algumas línguas, a centralidade ou não de algumas culturas e os vários agentes e influências que podem determinar o lançamento de um livro no exterior e seu destino no contexto literário internacional: prefácios de pessoas famosas, prêmios concedidos, apoios institucionais e agentes culturais: diplomatas, tradutores, poliglotas, agências literárias, entre muitos outros.

Embora fale a partir de um centro hegemônico, a autora se ocupa de muitos autores de diferentes origens, de culturas periféricas e centrais. Casanova está interessada em descrever um cenário mundial em que diferentes centros literários concorrem por um lugar de reconhecimento internacional. Ela menciona autores de muitos países, que escrevem em várias línguas. Seu índice onomástico cita mais de 600 autores, talvez 700. Ela privilegia uma visão competitiva desse mundo literário e rejeita a ideia de obras literárias "puras", desvinculadas de seu contexto social e político:

\begin{abstract}
A ideia pura de uma literatura pura dominar o mundo literário favorece a dissolução de todos os vestígios da violência invisível que nele reina, a denegação das relações de força específicas e das batalhas literárias. [...] É nas regiões mais autônomas, liberadas de certa forma das coerções políticas, que se inventam a ficção de uma literatura emancipada de todas as amarras históricas e políticas, a crença em uma definição pura da literatura, separada até de qualquer relação com a história, o mundo, a nação, o combate político e nacional, a dependência econômica, o domínio linguístico, e a ideia de uma literatura universal, não nacional, não particularista e independente dos recortes políticos e linguísticos (CASANOVA, 2002, p. 63).
\end{abstract}

A autora insiste na importância da tradução para que se possa trazer a uma dimensão internacional obras que vêm de países menores. Mais que isso, para ela ser traduzido é um indicativo de que determinado autor está a caminho de ser reconhecido em outros países, ou já conseguiu fazê-lo.

A tradução é a grande instância de consagração específica do universo literário. Desdenhada como tal por sua aparente neutralidade, ela é contudo a via de acesso principal ao universo literário para todos os escritores "excêntricos": é uma forma de reconhecimento literário e não uma simples mudança de língua, puro intercâmbio horizontal que se poderia (deveria) quantificar para tomar conhecimento do volume das transações editoriais no mundo. A 
tradução é, ao contrário, o maior desafio e a arma primordial da rivalidade universal entre os jogadores, uma das formas específicas da luta no espaço literário internacional, instrumento de geometria variável cujo uso difere de acordo com a posição do tradutor e do texto traduzido (CASANOVA, 2002, p. 169).

Outra obra que merece ser mencionada nesta discussão sobre a literatura mundial, já que no próprio título menciona a tradução, é Against World Literature: on the politics of untranslatability de Emily Apter. Esse título provocativo poderia dar a ideia de que a autora é contra a tradução: se ela defende o intraduzível, como existiria um intercâmbio de obras literárias entre países diferentes? Entretanto, a leitura da obra nos revela que na verdade ela se posiciona contra uma possível pasteurização das obras com o intuito de agradar ao leitor estrangeiro e obter sucesso nas vendas. Nas palavras de Emily Apter:

I endorse World Literature's deprovincialization of the canon and the way in which, at its best, it draws on translation to deliver surprising cognitive landscapes hailing from inaccessible linguistic folds [...] However, I do harbor serious reservations about tendencies in World Literature toward reflexive endorsement of cultural equivalence and substitutability, or toward the celebration of nationally and ethnically branded "differences" that have been nichemarketed as commercialized 1identities." (APTER, 2013, pos. 75-91).

A autora defende uma abordagem da literatura comparada que reconheça a importância da não tradução, da tradução equivocada, da incomparabilidade e intraduzibilidade (APTER, 2013, pos. 112). Essa é uma questão pertinente no caso da literatura brasileira, já que existe uma pressão por parte dos editores estadunidenses, por exemplo, a interferir na obra e desfigurá-la em nome de uma "vendabilidade". Outra dimensão da proposta de Apter é entender o intraduzível não como o oposto do sempre traduzível, mas como uma forma linguística de fracasso criativo com usos homeopáticos (APTER, 2013, pos. 367).

É dessa perspectiva, que não ignora o caráter competitivo da "República Mundial das Letras" nem a desigualdade entre os diversos centros literários, que vamos agora analisar cartas importantes trocadas entre a tradutora Harriet de Onís e os editores e pareceristas da editora que publicou The devil to pay in the backlands.

\section{UM MOMENTO DE CRISE}

Em 2 de abril de 1962, três anos após ter firmado contrato para a tradução de Grande sertão: veredas para o inglês, Alfred Knopf escreve uma longa carta a Harriet de Onís enumerando queixas em relação ao trabalho dela. Vamos aqui nos limitar às acusações feitas em relação à obra de Rosa. 
Now look at the recent history of our business together. You fell head over heels in enthusiasm for the Guimarães Rosa novel and we violated almost the first rule of publishing judgement by buying the book on your say-so alone. Just the same, that was a measure of our confidence in you.

Then you undertook to do the translation, only to find out that you had bitten off more than you could chew. You then recommended us to Professor Taylor, with results even more disastrous than have ever been explained to you (AK para $\mathrm{HdO}, 02 / 04 / 1962)$.

Os "resultados desastrosos" a que se refere Knopf dizem respeito à tradução entregue à editora pelo Professor James Taylor cerca de um ano antes. De Onís concordara em ler e avaliar a tradução de Taylor. No dia 17 de março de 1961, ela envia uma carta a Knopf com uma avaliação da tradução de Taylor, que ela diz estar muito boa, usando termos como "superlative job", "a wonderful evocation of the original". Ela afirma não ter podido ler o texto completo, tendo feito isso por meio de amostras selecionadas de várias partes do livro. Existem pequenos erros de digitação, mas Knopf pode sentir orgulho da obra que irá publicar ( $\mathrm{HdO}$ para $\mathrm{AK}$, 17/03/1961).

Proponho aqui um salto para o passado, um flash-back para cerca de um ano antes, para depois retomarmos essa significativa carta de Knopf para Harriet de Onís, datada de abril de 1962.

Depois que Harriet entrega sua avaliação de The devil em março de 1961, entra em cena a Sra. Judith Jones, que trabalhava na editora como uma espécie de parecerista externa, para quem é enviado o "manuscrito", ou seja, a tradução de Grande sertão iniciada por de Onís e finalizada por James Taylor, juntamente com a avaliação de Harriet de Onís. Mais de um mês depois, no dia 25 de abril, de Onís escreve para o editor William Koshland registrando o "grande manto de silêncio" (great pall of silence) que está cobrindo a editora (HdO para WK, 25/03/1961): várias semanas haviam se passado, e de Onís não recebera nenhum feedback sobre o material enviado em março.

Pedindo desculpas pela demora, Alfred Knopf escreve para de Onís em $1^{\circ}$. de maio, informando-a de que a tradução fora enviada para uma "leitora" externa (justamente a Sra. Jones) e que o julgamento dela foi totalmente negativo: "she found it absolutely impossibly - shall I say inadequate?" (AK para HdO, 01/05/1961). Knopf e Jones acharam por bem comunicar esse julgamento ao Professor Taylor, que nesse momento ainda não lhes tinha respondido. Nessa carta, ele anexa o parecer feito por Jones.

Em 8 de maio de Onís escreve para Judith Jones dizendo que acha que Taylor fez um bom trabalho e tenta lhe explicar características da obra: 


\begin{abstract}
May I point out to you that the hero, the narrator, is talking to an educated man of the city on whom he wants to make a good impression. Moreover, he is proud of such book learning as he has been able to acquire, and tries to display it whenever he can. But he does lack the vocabulary for the philosophic and religious questions that trouble him, and has trouble mobilizing his ideas. It is, in a sense, a foreign language he is using, for as you yourself point out, there is a change when he is dealing with action or descriptive passages ( $\mathrm{HdO}$ para $\mathrm{JJ}$, 08/05/1961)
\end{abstract}

De Onís argumenta também que a linguagem de Rosa tende para o arcaico porque na região onde se passa a história prevalece uma forma mais antiga de português e que foi isso que Taylor tentou reproduzir. Lembra também que Guimarães Rosa é um autor muito considerado no Brasil, e que ele sabe muito bem o que está fazendo, "he knows exactly what he is about". Ela acha que Taylor não vai se opor às sugestões de mudança, mas que algumas coisas que desagradaram a Jones devem permanecer, para que se faça justiça ao autor. Diz que o estilo dele deve ser respeitado, "one must respect his style".

Num tom sempre polido, ela encerra a carta nos seguintes termos, mostrando que entende a preocupação de Jones, mas insistindo que não se deve simplificar demais o autor:

Do forgive me for what seems a lecture, but I thought it would help you to have this background. Naturally, it is important for the reader to be able to go along without being tripped up; but many great books are not easy reading (HdO para JJ, 08/05/1961).

Vale a pena lembrar que Harriet de Onís, apesar de ter-se apaixonado por Rosa após ter lido uma tradução de "A hora e a vez de Augusto Matraga", relutou muito antes de aceitar a tarefa de traduzir o livro, e só o fez mediante muita insistência da editora e do próprio marido. Seis meses após ter começado o trabalho, de Onís desistiu de continuá-lo e o transferiu para o Professor James Taylor, pois se sentia inadequada para completar a tarefa, entre outros motivos por Rosa não estar em condições de ajudá-la e também porque o "arranjo" que o autor havia proposto, colocando a Sra. Nina Oliver como uma espécie de intermediária entre eles, não produziu bons resultados (VERLANGIERI, 1993, p. 19). Apesar dessa atitude, de Onís não conseguiu se desligar do livro, que ainda the deu muito trabalho por cerca de mais um ano. Na pasta 327.7 do arquivo de Alfred Knopf, que está abrigado no Harry Ransom Center da Universidade do Texas em Austin, é possível acompanhar pelas cartas trocadas o mal-estar que se instaurou. Taylor parece não ter ficado nada feliz com a reprovação de sua tradução e diz que, exceto ele, ninguém seria capaz de fazer a tradução. Knopf se precaveu junto ao advogado da editora para evitar que fosse criada uma questão legal. 
Em 15 de maio de 1961 e no mesmo tom polido, Judith Jones responde a Harriet de Onís dizendo que o argumento dela é muito bem fundamentado, mas ela ainda se preocupa: "But it still leaves me wondering what one does when the final result in English seems for long stretches so painfully cumbersome to read" (JJ para $\mathrm{HdO}, 15 / 05 / 1961)$. Jones envia também um memorando para Knopf comentando a carta de de Onís e dizendo o que ela acha que Taylor deveria fazer: simplificar a sintaxe, de modo que não se transformasse num obstáculo a cada sentença. Depois, onde fosse necessário, ele poderia polvilhar a narrativa ("sprinkle the narrative") com elementos de conversa empolada ("postured talk") usada para impressionar o homem da cidade - apenas o suficiente para conferir o sabor dessa conversa (JJ para AK, sem data).

Nesse ponto algumas coisas estão já claras: $1^{\circ}$.: Knopf e a leitora Judith Jones não aceitam a inventividade linguística de Rosa, por mais que a tradução tenha "distorcido e interpretado mal o texto em português de uma forma consistente" (KRAUSE, 2013, p. 209) ; $2^{\circ}$ : a tradução, embora não esteja tão literal quanto Rosa desejava, ainda soa bastante sui generis em inglês, portanto não é tanto assim um "more readily digestible text", como aponta Armstrong (2001, p. 72); $3^{\circ}$ : : Harriet de Onís lutou como pôde, e com bastante afinco, para defender na tradução um certo desvio em relação a uma linguagem fluida e comum. E fez isso até que a obra foi publicada, sempre diplomaticamente.

Em 5 de julho de 1961, Knopf envia a de Onís uma longa carta relatando os problemas que está enfrentando com Taylor. Taylor mandou para o advogado da editora uma carta com a avaliação que recebeu de Harriet de Onís, dizendolhe como ele tinha feito um bom trabalho na tradução. Taylor reafirma que ninguém senão ele poderia ter feito essa tradução e que no Brasil, embora haja tanto comentário positivo, ninguém é capaz de ler a obra em português. Taylor não admite que Harriet de Onís apareça como cotradutora do livro, diz que a obra é praticamente intraduzível e, se a tradução é difícil de ler, o original também é (AK para $\mathrm{HdO}, 05 / 07 / 1961)$.

No dia seguinte Harriet de Onís responde assumindo para si parte da responsabilidade e oferecendo-se para fazer uma revisão do texto. Ela não faz questão de seu nome aparecer como tradutora ou cotradutora, o que pode apaziguar as coisas com Taylor. Ela também enfatiza a situação difícil em que a editora ficaria diante de Guimarães Rosa se desistisse de publicar o livro, o que também mancharia as relações da A. A. Knopf com o Brasil.

De Onís diz ainda que Taylor não está certo ao dizer que a obra é intraduzível. Ela é difícil, como são muitas narrativas que têm fluxo de consciência. Mesmo com 
toda essa disposição para pôr panos quentes numa situação que parece insustentável (Knopf em sua carta chega a mencionar a possibilidade de desistirem de publicar o livro), ela não deixa de dar sua opinião ao encerrar a carta:

The only disagreeable thing I am going to say - and I don't feel the least bit disagreeable, but relieved to have thought of a solution - because honesty often resembles disagreeableness, is that I think you are being a bit too sticky about this translation. I have told you all along that I did not think it nearly as bad as your people did. At the same time I must tell that I have been amazed, not to say dismayed, by every one of the Camus translations you have published, and one of the things I want to do is read him in the original when I have time. I cannot believe that an author as sensitive and original as Camus could possibly write in such a pedestrian manner, and people who have read him in the original assure me that he does not. So don't be quite so hard on Mr. Taylor. And don't be cross with me for saying this (HdO para AK, 05/07/1961).

No dia seguinte de Onís manda outra carta para Knopf, estendendo sua argumentação da carta anterior, que fora muito esquemática ("sketchy"). Ela diz que recomendou Rosa à editora com base na sua opinião e em tudo o que leu sobre a obra. Ela acha difícil acreditar que Taylor tenha afirmado que ninguém no Brasil conseguia ler a obra, já que o livro tinha tido várias edições e as pessoas não compram livros para não os ler. Diz também que o editor Herbert Weinstock lhe escreveu dizendo que o Sr. Nabuco ${ }^{4}$ passou pela editora e, indagado sobre o livro, disse que era uma grande obra, mas expressou dúvida sobre sua traduzibilidade. Weinstock então argumentou que se Ulysses pôde ser traduzido para o francês, praticamente qualquer livro poderia ser traduzido.

A isso Harriet de Onís acrescenta que se admira diante do fato de Faulkner, autor muito admirado por ela, ter sido traduzido em tantas línguas e ter exercido a influência que exerceu. Sobre o arrependimento manifestado por Knopf em relação a ter resolvido comprar os direitos de tradução de Grande sertão: veredas com base apenas na opinião de um leitor (de Onís), ela diz que supondo que dois leitores tivessem concordado com relação ao valor do livro, Knopf ainda estaria na mesma situação, já que não lê português. Ela reforça a proposta de fazer a revisão do texto de Taylor e diz que não quer receber nada por isso. "This will be my contribution for the Alliance for Progress".

Além da argumentação racional, de Onís argumenta também retoricamente, jogando aqui e ali alguma ironia. Quando muda de assunto e aborda a viagem que Knopf pretende fazer para a América Latina, ela oferece suas impressões e, após uma frase, escreve, entre parênteses, "Excuse me, that sentence doesn't have a

4. Provavelmente Maurício Nabuco (1891-1979), filho de Joaquim Nabuco, que foi embaixador do Brasil nos EUA entre 1948 e 1951). 
verb". A frase é, como se diz, um "tapa com luva de pelica" em quem reclamou que as frases de Rosa são truncadas e incompletas (HdO para AK, 07/07/1961). Evidenciando que Knopf encaminhou essa carta de de Onís para a leitora Judith Jones, esta última escreve para Knopf em 08 de julho dizendo que acha a proposta de de Onís muito sensata. Jones sugere, no entanto, que eles (provavelmente ela, ou ela e Knopf) recuperem o texto e façam a revisão de 20 ou 30 páginas, para que Harriet entenda direito o que eles querem. Nessa carta fica explícito que existe ainda outra pessoa envolvida na avaliação da tradução de Taylor, um certo Gregory (JJ para AK, 08/07/1961). Em 10 de julho de 1961 Knopf responde a de Onís, reconhecendo o gesto dela como "magnanimous to the nth degree" (AK para $\mathrm{HdO}$, 10/07/1961).

Em 21 de julho Harriet de Onís escreve para Guimarães Rosa informando-o de que Taylor terminou a tradução, mas que todos na editora julgam melhor que ela, que conhece bem a obra, faça uma revisão. Ela, porém, não poderá começar esse trabalho imediatamente, porque teve problemas de saúde associados ao excesso de trabalho e também dificuldades com uma antiga úlcera que voltou a incomodá-la (HdO para GR, 21/07/1961).

Inicia-se então uma nova fase de muito trabalho. Em várias de suas cartas, Harriet de Onís se refere a três obras em que está trabalhando: Sobrados e mucambos de Gilberto Freyre, que ela deve traduzir e editar, ou seja reduzir à metade; Grande sertão: veredas, de Rosa, e Las lanzas coloradas, do autor venezuelano Arturo Uslar-Pietri. Em cartas que troca principalmente com o editor William Koshland, de Onís registra como é tedioso o trabalho com a revisão da tradução de Taylor, e como Freyre é repetitivo.

Nosso flash-back se encerra aqui, visto que estamos próximos da data em que Knopf envia para Harriet a notória carta a que nos referimos no início desta seção, com acusações pesadas contra ela e seu trabalho. Saltamos de volta para 22 de março de 1962, quando de Onís relata em uma carta a Koshland que acabou de enviar a Knopf a versão duplamente revisada do texto de Rosa, que se sente como um prisioneiro que ganhou a liberdade ("a convict out of stir") e que o período em que esteve envolvida com Rosa foi para ela uma pena de dois anos ("a two year sentence") (HdO para WK, 22/03/1962).

Mal sabe ela que um novo ciclo de discussões com os editores e revisões está prestes a começar, até que The devil to pay in the backlands seja publicado em abril de 1963. Retomemos enfim a longa carta que Knopf enviou para Harriet de Onís, em 1962, enumerando queixas sobre o trabalho dela e enfocando a (duplamente revisada, nessas alturas) tradução do texto de Rosa. Depois de todas as reclamações 
sobre os conselhos errados que ela deu (sobre o livro de Rosa e o de Uslar-Pietri, cuja tradução ele classifica como "abominável"), Knopf pede que ela não responda àquela carta imediatamente, e que reflita bastante antes de fazê-lo (AK para $\mathrm{HdO}$, 02/04/1962).

Harriet de Onís responde dois dias depois, dizendo que ficar exasperada não é uma de suas falhas, e que ela concorda que está trabalhando demais, mas o que sofreu com isso foi a sua saúde, não as suas traduções. Ela não trabalha só pelo dinheiro, que nem é tanto assim. Expressa seu grande interesse em trazer à atenção do público americano as obras de autores da América Latina, e acredita estar com isso fazendo algo útil. Ela explica que não continuou a tradução da obra porque Rosa disse que não poderia ajudá-la e sugeriu que isso fosse feito pela Sra. Oliver. Ela responde a cada uma das queixas de Knopf e termina dizendo que em relação ao livro de Uslar-Pietri ele deve decidir o que fazer, e que no caso dos outros livros (de Rosa e Freyre), devem trabalhar neles até que fiquem satisfatórios para os editores. Ela está disponível para fazer isso (HdO para AK, 04/04/1962).

A essa, Knopf responde com outra longa carta retomando o que tinha dito e, no caso de Rosa, mostra-se surpreso, já que ele e Rosa se entenderam tão bem, tendo se encontrado quatro vezes na semana em que Knopf esteve no Rio de Janeiro. Knopf lamenta não ter sabido melhor das dificuldades que Harriet enfrentou com Rosa. De qualquer forma, ainda quer ter um conhecimento detalhado delas (AK para $\mathrm{HdO}, 06 / 04 / 1963)$.

Em 9 de abril Harriet escreve uma também longa carta com um trecho transcrito de carta de Guimarães Rosa, em abril de 1959, dizendo que não poderia mais ajudá-la com as traduções, porque teve um problema cardíaco e precisa cuidar da saúde, não podendo ficar no estado de nervosismo em que ficou quando os dois trocaram várias cartas discutindo a tradução de "O duelo". Que Rosa sugeriu a intermediação da Sra. Oliver que, apesar de ter se esforçado, não ajudou muito (HdO para AK, 09/04/1962).

Em 13 de abril ele responde, dizendo que quando esteve com Rosa este não comentou nada daquilo, nem sobre sua saúde, nem sobre a Sra. Oliver. Declarase atônito. Diz também que o inglês de Rosa é bastante bom. Lamenta não ter sabido de todo o processo com detalhes antes e entende por que Harriet não pôde continuar a tradução (AK para $\mathrm{HdO}, 13 / 04 / 1962)$.

(É importante frisar que, paralelamente à discussão sobre a tradução do livro de Rosa, Knopf e de Onís estão também trocando cartas referentes ao livro de Gilberto Freyre, com cuja tradução os editores estão igualmente desgostosos). 
Em 13 de abril de 1962 Harriet escreve à Sra. Jones acusando o recebimento de uma carta do dia $9 \mathrm{com}$ as primeiras 100 páginas da tradução de Grande sertão: veredas revisadas. Diz que gostou de algumas sugestões, não pôde aceitar outras e, em alguns casos, diante do que Jones propôs ela indicou uma terceira possibilidade. Em seguida, ela prossegue:

As I say, many of the changes are good. But I think that, by and large, you have a tendency to want to tidy it up too much, and I feel that is a mistake. Think back on Molly Bloom's soliloquy at the end of Ulysses - and Joyce has had a powerful influence on Guimarães Rosa - and I think you will see what I mean. This long monologue has to be somewhat rough and incoherent in spots, for it is an old man trying to get at the truth of his experiences and beliefs, hampered by his doubts and lack of ability to express and order them (HdO para JJ, 13/04/1962).

Em 19 de abril a Sra. Jones responde, dizendo que Harriet parece não ter entendido algumas observações dela, e que quando ela (Jones) colocou na margem do texto um ponto de interrogação ou um pequeno " $\mathrm{x}$ ", ela queria dizer que a frase estava obscura e esperava que Harriet a esclarecesse. Ela observa que é difícil fazer sugestões, porque ela não sabe português. Jones diz também que as decisões finais em relação ao texto são de Harriet.

Em 21 de maio de 1962 a Sra. Jones envia o texto completo revisado e diz que as últimas 200 páginas foram mais fáceis porque ela entendeu que tipo de sugestão é útil para Harriet. Esse trecho tem muito menos correções, provavelmente porque a parte final tem mais ação e o estilo fica "somewhat more precise", e também porque "also, one gets used to stylistic peculiarities and resists them less". Mesmo assim, tem coisas que ainda a incomodam... "many small stylistic mannerisms":

For instance, I find annoying, probably because they are repeated so often, Rosa's habit of backing into sentences with structures like "What I mean is...." Also, there seem to be too many verbs that should have an object and instead are simply left hanging; too many "there"s that do not refer to anything precise; many phrases like "those two" and "that one" or simply "the ones" that seem so unnatural in English. I think you will see what I mean as you go along (JJ para $\mathrm{HdO}, 21 / 05 / 1962$ ).

Harriet responde a ela em 26 de maio e diz que concorda com tudo o que ela diz e vai ter em mente as recomendações da leitora quando revisar mais uma vez o trabalho. Diz ainda, usando de sua diplomacia, que gostaria imensamente de ler um livro sobre culinária que a aguarda na estante, mas não pode fazer isso porque ainda está trabalhando com as obras de Freyre e Rosa. É um modo de se aproximar da Sra. Jones, que trabalhou na produção do tal livro (HdO para JJ, 26/05/1962).

Dias depois, entretanto, Harriet envia para Knopf uma carta que tem um forte tom de desabafo, dizendo que não pode aceitar a maioria das mudanças propostas 
nos dois livros. No caso de Freyre, os editores empregaram não uma caneta azul, mas uma machadinha.

Ela retoma a carta dele de 2 de abril, agora de fato respondendo a tudo depois de refletir bastante. Diz que não é por dinheiro que está fazendo esse trabalho, que tem recusado ofertas de outras editoras, que lhe pagariam mais. Ela acredita estar cumprindo uma função útil ("a useful function"). Diz também que os problemas dela começaram depois que o editor Herbert Weinstock foi embora. No tempo dele, ela recebia muitos elogios. No caso de Rosa, ela acha que a maioria das sugestões são "picuinhas":

I have also received the revised ms. of Guimarães Rosa from Mrs. Jones. I have only had time to glance over it, and I in no way blame her, but the work that has gone into it is, if you will forgive the expression, in the nature of nit picking, and I cannot accept the majority of the changes she suggests. This is a book of great quality, but strange and difficult, as you were told when you were in Brazil. It will have to stand or fall by its own merits, not by the tidying up we try to do. The same holds true of Joyce and Faulkner, to cite only two examples. What would have happened if their publishers had gone to straighten out and reorganize their thought and expression? They are all artists that are fully aware of what they are doing, and whose style is an integral part of their work. You were extremely, and, for the most part, undeservedly, harsh with Mr. Taylor. You are completely in your right not to like Guimarães Rosa's writing. But do not try to make him over in your own likeness (HdO para AK, 03/06/1963).

Três dias depois Knopf escreve a Harriet dizendo que gostaria que ela fosse até a editora para uma reunião com os dois revisores, Judith Jones e Henry Robbins trazendo algumas folhas dos textos revisados para mostrar a eles as correções com as quais não concorda (AK para $\mathrm{HdO}, 06 / 06 / 1962)$. Em 7 de junho Knopf complementa a carta do dia anterior apresentando mais um problema nos prefácios do Freyre. No final ele diz que se ele (Knopf) propuser outro livro desse tipo, ela pode dar um tiro nele.

Isso indica que os argumentos dela foram ouvidos por Knopf, que parece querer buscar uma solução conciliadora para todo o conflito. Harriet, por sua vez, apesar de algumas vezes concordar com os revisores e recuar de sua posição, logo a retoma com veemência e, ao mesmo tempo, com polidez.

No dia 9 de junho ela responde que não gostaria de apontar diretamente para os editores o que lhe desagrada nas revisões; prefere apontá-las para Knopf, que poderá então discuti-las com eles. É uma forma de evitar um confronto que poderia ser desagradável ("save face"). E referindo-se à "autorização" de Knopf para que ela atire nele, ela termina a carta assim:

I am not a good shot and I don't know whether you are. We'd probably just mess one another up. I think we've learned our lesson. Let's see if we can conclude this chore gracefully and satisfactorily. We will charge it off to experience (HdO para AK, 09/06/1962). 
Uma carta de Knopf para de Onís datada de 15 de junho de 1962 registra que eles se encontraram pessoalmente no dia anterior, e ele diz que todos sairão dessa fase difícil em breve. Será necessário redatilografar o texto de Rosa, e Knopf pede que ela o leia ainda mais uma vez (AK para $\mathrm{HdO}, 1506 / 1962)$, o que ela aceita fazer alguns dias depois (HdO para AK, 18/061962). Desse ponto em diante, os conflitos parecem ir diminuindo, embora haja ainda muito trabalho pela frente.

Ela participa do final da produção do livro, propondo o título The devil to pay in the backlands, sugerindo que Jorge Amado escreva um prefácio, oferecendose ela mesma para escrever uma introdução, na qual compararia Rosa a Faulkner e Melville. Em 29 de julho ela chama a atenção de Knopf para a última palavra do livro, "Travessia".

Mrs. Jones did not like the final sentence which, if I remember correctly, read: "The passage". She found it weak and, I believe, inconclusive, and inasmuch I had not accepted so many of her suggestions, I decided to go along with that one. But all the time it has been worrying and niggling at me. I was convinced it was there for a very definite purpose. And then the other day I came on a phrase from Montaigne in The London Times Supplement: "I describe not the essence, but the passage". I'd be willing to bet my bottom dollar that this is what Guimarães Rosa had in mind - I'd also bet he is a dedicated reader of Montaigne, who is one of my favorite writers - and his use of the phrase is an artful device, in the fullest meaning of the term, as Velázquez's painting himself, painting, into his greatest picture, Las Meninas. We must let it stand. Our defense for our corrections is that this is a translation; otherwise he'd be justified to say as Faulkner did to the person who was trying to smooth out The sound and the fury: "Who the hell do you think you are?". But Guimarães Rosa is too sweet to say that. I am more and more convinced of his greatness (HdO para AK, 29/07/1962).

Em 10 de dezembro de 1962, Harriet de Onís escreve para William Koshland dizendo que finalmente enviou as provas de The devil to pay in the backlands e que se sente aliviada:

I returned the page proofs of The devil to pay in the backlands to Mr. Jacobs this morning. It was a long a tedious job that I am glad to have out of the way because I will need every minute of this over-busy holiday season to get ready for the trip to South America (HdO para WK, $10 / 12 / 1962)$

O livro, como se sabe, foi publicado apenas em abril de 1963, devido a uma greve de tipógrafos que prestavam serviço para a A. A. Knopf (VERLANGIERI, 1993, p. 20). Não foi tão apreciado nos Estados Unidos nem foi muito vendido, mas a partir da tradução para o inglês ele foi, como Rosa supunha que aconteceria, catapultado para vários países europeus (VERLANGIERI, 1993, p. 30).

Acompanhando as trocas de cartas de Harriet de Onís e seus vários parceiros na feitura de Grande sertão: veredas em inglês, pudemos ver como ela se envolveu com o autor e tentou defender, até onde possível, a singularidade de sua escrita. A 
tradução não reproduz toda a riqueza do texto em português, mas foi importante na divulgação da obra, e o próprio Rosa se mostrava, ao mesmo tempo, apegado ao seu texto e disposto a abrir mão de suas peculiaridades, em função da oportunidade de ser publicado em outras línguas.

\section{APONTAMENTOS FINAIS}

A ideia para esse trabalho já existia há bastante tempo em forma de sugestão, ou até de um incômodo, toda vez que ouvíamos críticas à tradução inglesa de Grande sertão: veredas, principalmente quando as críticas pareciam ser feitas sem que o crítico tivesse verdadeiro conhecimento de causa. Contra si Harriet de Onís e James Taylor tinham uma série de fatores, como já foi dito: havia alguns estudos críticos sobre a obra, mas nem de perto na quantidade que existe hoje. O recurso tecnológico mais avançado de que eles dispunham era a máquina de escrever. E como Harriet escreveu cartas! Frequentemente mais de uma para a mesma pessoa no mesmo dia.

A seu favor eles tinham Rosa relativamente disponível e desejando muito ser traduzido. Uma pertinente questão levantada por Victoria Livingstone diz respeito ao fato de o português ser uma língua periférica em relação ao inglês, numa época em que o Brasil e sua cultura eram muito menos conhecidos pelos outros países, o que nos remete à discussão de Pascale Casanova sobre a dominação de alguns centros literários sobre outros:

A translator of Joyce into Portuguese may have more freedom because Joyce is already established in the canon of world literature and recognized as an experimental writer. At the time de Onís translated Grande sertão: veredas, Rosa was not a well-known writer outside of Brazil. An experimental English version of an already dense and difficult text may not have been accepted in the U.S. market without the writer already having an established reputation (LIVINGSTONE, 2015, p. 125).

James R. Krause $(2015,2013)$ defende a ideia de que a tradução "não deu certo" porque foi feita por mais de uma pessoa: "sem dúvida, Taylor teria produzido uma tradução totalmente distinta se tivesse partido do zero, mas não pôde e o resultado foi uma tradução feita por quatro pessoas" (KRAUSE, 2013, p.229). A hipótese de Krause pode fazer sentido, mas com a análise feita aqui, das cartas entre Harriet de Onís e seus editores, tomamos conhecimento de que mais pessoas participaram da tradução: Além de Harriet de Onís, do Professor James Taylor, da Sra. Nina Oliver e do próprio Guimarães Rosa, "meteram a colher" na tradução (para continuarmos na metáfora culinária mencionada por Krause) ${ }^{5}$, também Judith

5. Na verdade, a metáfora culinária foi usada por Harriet de Onís para se referir ao fato de várias pessoas participarem da tradução. De Onís usou o ditado "Too many cooks spoil the broth" em 
Jones, Henry Robbins, o próprio Alfred Knopf e provavelmente mais uma pessoa, que talvez não tenha tido uma atuação tão decisiva e que é referida pelo nome Gregory. A tradução foi negociada a cada etapa e nas negociações a atuação de Onís foi fundamental para que o processo fosse adiante.

O Professor Taylor não recebeu com a mesma tranquilidade que de Onís o parecer negativo de sua tradução, e começou a fazer exigências (ser o único a aparecer no livro como tradutor, por exemplo) e mandando cartas perturbadoras para Knopf. De Onís abriu mão de seu nome no livro e prontificou-se a revisar o trabalho, o que foi aceito por Taylor, facilitando muito as coisas. No final, o próprio Taylor fez questão de que o nome dela aparecesse juntamente com o dele. Tivesse Taylor exigido até o final que fosse o único indicado como tradutor, de Onís provavelmente teria sido deixada em paz. Mas já que não foi, a memória dela merece este desagravo.

O que vamos dizer agora pode ser uma platitude, mas a tradução de Grande sertão: veredas para o inglês foi o que pôde ser. Nos termos de Yves Gambier, ela realizou o afastamento inicial que permitirá que a nova tradução se aproxime mais do texto em português.

A intenção deste trabalho foi iluminar certas características do processo que podem ter ficado em segundo plano. A nova tradução de Grande sertão: veredas agora em gestação já chamou a atenção de várias pessoas e de forma muito acolhedora. A tradutora poderá (e com certeza está fazendo isso) dispor de todos os recursos que lhe estão acessíveis. Além dos mais óbvios, como a fortuna crítica de Rosa, a Internet, a visita a Cordisburgo e muitas outras experiências, existem algumas joias das quais ela pode se valer, como um trabalho em que Stephanie Merrim sugere interessantes técnicas para recriar os "maneirismos" (como disse a Sra. Jones) de Rosa, em inglês.

A nova tradução não deve apagar The devil to pay in the backlands nem relegá-la ao ostracismo. The devil é uma importante precursora da nova tradução. E que venha a nova tradução, bem-vinda seja!

\section{REFERÊNCIAS}

ANDRADE, M. S. (2010). A palavra bravia: Linguagem e sentido na correspondência entre Guimarães Rosa e sua tradutora americana. Dissertação de Mestrado em Letras, PUC-RIO. Rio de Janeiro Disponível em: http://www2.dbd.puc-rio.br/pergamum/

carta a Guimarães Rosa datada de 2 de abril de 1964, em resposta ao comentário de Rosa, de que sua tradução de "O burrinho pedrês" havia superado a de Grande sertão (VERLANGIERI, p.259). 
biblioteca $/ \mathrm{php} /$ mostrateses.php? open $=1$ \&arqtese $=0812854$ _10_Indice.html. Acesso em: 28 dez. 2019, 131 pp.

APTER, E. (2013). Against World Literature: on the politics of untranslatability. Londres \& Nova York: Verso, Arquivo EPUB.

ARMSTRONG, P. (2001). Guimarães Rosa in translation: scrittore, editore, traduttore, traditore. Luso-Brazilian review, v. 38, n. 1, 2001, p. 63-87. Disponível em: https://www. jstor.org/stable/3513678. Acesso em: 13 nov. 2019.

ARMSTRONG, P. (1999). Third World literary fortunes: Brazilian culture and its international reception. Lewisburg: Bucknell University Press, (Edição Google Books, disponível em: https://play.google.com/books/reader?id=niqTDdlm4qkC\&hl=pt\&pg=GBS PA116.w.1.3.0. Acesso em: 20 nov. 2019.

BARBOSA, F. L. C. (2010). Leituras de 'Grande sertão veredas': sua tradução alemã e a correspondência de Guimarães Rosa com seu tradutor alemão Curt MeyerClason. Signótica, v. 22, n. 1, 2010, p. 57-68. Disponível em: http://hdl.handle. net/11449/124819. Acesso em: 31 dez. 2019.

BERTHOLD Zilly (2018). Transgermanização de 'Grande sertão: veredas'._LIS UFF. YouTube. 26 abr. 1h11m28s. Disponível em: https://www.youtube.com/ watch?v=fXrNLOdyCNI. Acesso em: 15 nov. 2019.

CARREIRO, M. N. (2017). "Quero que Guimarães Rosa conquiste quem leria James Joyce", diz tradutora de 'Grande sertão: veredas'. O Popular, 24 jun. 2017. Disponível em: https://www.opopular.com.br/noticias/magazine/quero-que-guimar\%C3\%A3esconquiste-quem-leria-james-joyce-diz-tradutora-de-grande-sert $\% \mathrm{C} 3 \% \mathrm{~A} 3 \mathrm{o}$ veredas-1.1298419. Acesso em: 27 abr. 2020.

CASANOVA, P. (2002). A república mundial das letras. Tradução de Marina Appenzeller. São Paulo: Estação Liberdade, 436 pp.

ESTEVES, B. (2012) O jagunço de Berlim. Revista Piauí, n. 67. Disponível em: https://piaui. folha.uol.com.br/materia/o-jagunco-de-munique/. Acesso em: 1 jan 2020.

ESTEVES, L. M. R. (2016) Uma discussão sobre a prática da retradução com base no caso das republicações de obras de Clarice Lispector no exterior. Trabalbos em Linguística Aplicada, v. 55, no. 3, p. 651-676. Disponível em: http://www.scielo.br/scielo. php? pid $=$ S0103-18132016000300651\&script $=$ sci_abstract\&tlng $=$ pt . Acesso em: 28 abr. 2020. 
"GRANDE sertão: veredas". (2014). Haroldo de Campos sobre Guimarães Rosa. ZekitchaCostello. YouTube. 2 mar. 44m28s. Disponível em: https://www.youtube. com/watch?v=tVTSZbWiyZA. Acesso em: 10 nov. 2019.

KRAUSE, J. A (2015). "Too many cooks spoil the broth": mistranslating 'Grande sertão: veredas' into oblivion. Chasqui, v. 44, n. 2, pp. 112-128. Disponível em: https://www. jstor.org/stable/24810763. Acesso em: 11 nov. 2019.

KRAUSE, J. A (2013) Aspirações irrealizadas: influências literárias e extraliterárias na tradução "falhada" de 'Grande sertão: veredas'. In: Torres, M.H.C.T; Freitas, L. F.; Monteiro, J. C. N. (orgs.) Clássicos em tradução: rotas e percursos. Florianópolis: PGET/ UFSC; Tubarão: Copiart, p. 215-233. Disponível em: https://www.academia. edu/3 $3530499 / \mathrm{Cl} \%$ C3\%A1ssicos_em_Tradu\%C3\%A7\%C3\%A3o_rotas_e_ percursos. Acesso em: 15 nov. 2019.

LIVINGSTONE, V. (2015). Translating Latin America: Harriet De Onís and the U.S. publishing market. Boston University Thesis and Dissertations. Disponível em https://hdl. handle.net/2144/14069. Acesso em: 17 nov. 2019, 212 pp.

MEME. (s.d.) DICIONÁRIO HOUAISS eletrônico. Disponível em: https://houaiss.uol.com.br/ pub/apps/www/v3-3/html/index.php\#1. Acesso em: 30 dez. 2019.

MEME (Internet). (s.d.) Wikipedia. Disponível em: https://pt.wikipedia.org/wiki/Meme (Internet). Acesso em: 30 dez. 2019.

MERRIM, S. (1982). In the wake of the word: translating Guimarães Rosa. Dispositio, v. 7, n. 19/21, (The Art and Science of Translation), p. 209-225. Disponível em: https:// www.jstor.org/stable/41491239. Acesso em: 13 nov. 2019.

PERRONE, C. A. (2003). A terceira margem do diabo: a recepção norte-americana da obra de João Guimarães Rosa. Itinerários, n. 21, p. 89-98.

PERRONE, C. A. (1987) João Guimarães Rosa - an endless passage. In: KING, J. (Ed.). Modern Latin American fiction: a survey. New York: Noonday. p. 117-35.

REBINSKI JÚNIOR, L. (s.d.) Especial capa: Grande sertão alemão. Cândido: Jornal da Biblioteca Pública do Paraná. Disponível em: http://www.candido.bpp.pr.gov.br/ modules/conteudo/conteudo.php? conteudo=249. Acesso em: 30 dez. 2019.

ROSTAGNO, I. (1977). Searching for recognition: The promotion of Latin American literature in the United States. Westport, CT: Greenwood Press, 187 pp. 
VERLANGIERI, I. V. R. (1993). João Guimarães Rosa - correspondência inédita com a tradutora norteamericana Harriet de Onís. Dissertação de Mestrado em Letras - Estudos Literários UNESP Araraquara, 357 pp.

VINCENT, J. S. (1978). 'Grande sertão: veredas'. The critical imperative. In: João Guimarães Rosa. Boston: Twayne Publishers, 182 pp.

VIOTTI, F. B. (2007). Encenação do sujeito e indeterminação do mundo: um estudo das cartas de Guimarães Rosa e seus tradutores. Dissertação de Mestrado. Belo Horizonte: UFMG, 189 pp. Disponível em: https://repositorio.ufmg.br/bitstream/1843/ECAP . 74BGSH/1/dissertacao_fernando_viotti.pdf. Acesso em: 26 dez. 2019.

Recebido: 28/2/2020

Aceito: 13/7/2020

Publicado: 20/7/2020 